\title{
Extrahepatic Bile Duct Mucinous Cystic Neoplasm with an Associated Invasive Carcinoma
}

National Cancer Institute

\section{Source}

National Cancer Institute. Extrahepatic Bile Duct Mucinous Cystic Neoplasm with an

Associated Invasive Carcinoma. NCI Thesaurus. Code C96946.

A mucinous cystic neoplasm that arises from the extrahepatic bile ducts and it is associated with an invasive carcinomatous component. 